\title{
MANIFESTATION OF STRUCTURE AND INTERMOLECULAR INTERACTIONS OF BIOLOGICALLY ACTIVE BRASSINOSTEROIDS IN INFRARED SPECTRA
}

\author{
N. A. Borisevich, ${ }^{1}$ I. V. Skornyakov, ${ }^{* 1}$ \\ V. A. Khripach, ${ }^{2}$ G. B. Tolstorozhev, ${ }^{1}$ \\ and V. N. Zhabinskii ${ }^{2}$
}

UDC 547;535.34;543.42.

\begin{abstract}
We have analyzed the IR spectra obtained for steroidal phytohormones 24-epibrassinolide, 24-epicastasterone, 28-homobrassinolide, and 28-homocastasterone. The characteristic frequencies of the stretching vibrations of the hydrocarbon groups $\mathrm{CH}_{3}, \mathrm{CH}_{2}$, and $\mathrm{CH}$ and also the $\mathrm{C}=\mathrm{O}$ groups in the spectra of brassinolides are higher than in the spectra of castasterones, which makes it possible to identify them from the IR spectra. Study of the spectra of these brassinosteroids in different media (pressed samples in $\mathrm{KBr}$, films, solutions in $\mathrm{CHCl}_{3}$ and $\mathrm{CDCl}_{3}$ ) allowed us to establish the presence of intermolecular interactions in which $\mathrm{C}=\mathrm{O}$ and $\mathrm{OH}$ groups, $\mathrm{OH}-\mathrm{OH}$ groups participate, and also the possible formation of intramolecular hydrogen bonds between the $\mathrm{OH}$ groups of the molecules.
\end{abstract}

Key words: IR spectrum, brassinosteroid, brassinolide, castasterone, characteristic frequencies, intermolecular and intramolecular bonds.

Introduction. Brassinosteroids are a new class of natural and synthetic steroidal phytohormones [1] which play a key role in regulation of the growth and development of plants, and also have good prospects for use in medicine and veterinary practice as new pharmacological agents. A condition for high biological activity of brassinosteroids is the presence in the $B$ ring of a 6-keto (castasterone and related compounds) or 7-oxa-6-keto (brassinolide and other lactones) structural moiety, and also a $2 \alpha, 3 \alpha$-diol group on the $A$ ring and a trans fusion for the $A / B$ rings (see structural formulas). Along with these structural features, the biological activity of brassinosteroids is determined by the structure of the side chain: the presence and configurations of hydroxyl groups at the carbon atoms C 22 and C 23, and also the nature of the substituent at the carbon atom C 24 [2-4]. It has been established that the greatest biological activity in many test systems is shown by brassinolide, first obtained from pollen of the plant Brassica napus [5]. However, a clear interconnection between the structure and the biological properties of brassinosteroids has not yet been established. This makes large-scale use of brassinosteroids in agriculture as plant growth stimulators difficult, and limits their advance into other areas of application.

Despite the fact that the IR spectra provide considerable information about the structure and interactions of molecules, in study of brassinosteroids, IR spectroscopy methods have been used mainly to confirm the course of chemical reactions in synthesis of new compounds in this class.

In this work, we used IR spectroscopy methods to study the structure and intermolecular interactions of 24epibrassinolide (1), 24-epicastasterone (2), 28-homobrassinolide (3), and 28-homocastasterone (4), the structural formulas of which have the form:

*To whom correspondence should be addressed.

${ }^{1}$ Institute of Molecular and Atomic Physics (State Scientific Institution), National Academy of Sciences of Belarus, 70 prosp. Nezavisimosti, Minsk 220072. E-mail: lirp@imaph.bas-net.by. ${ }^{2}$ Institute of Bioorganic Chemistry, National Academy of Sciences of Belarus, Minsk. Translated from Zhurnal Prikladnoi Spektroskopii, Vol. 74, No. 5, pp. 610-616, September-October, 2007. Original article submitted June 11, 2007. 

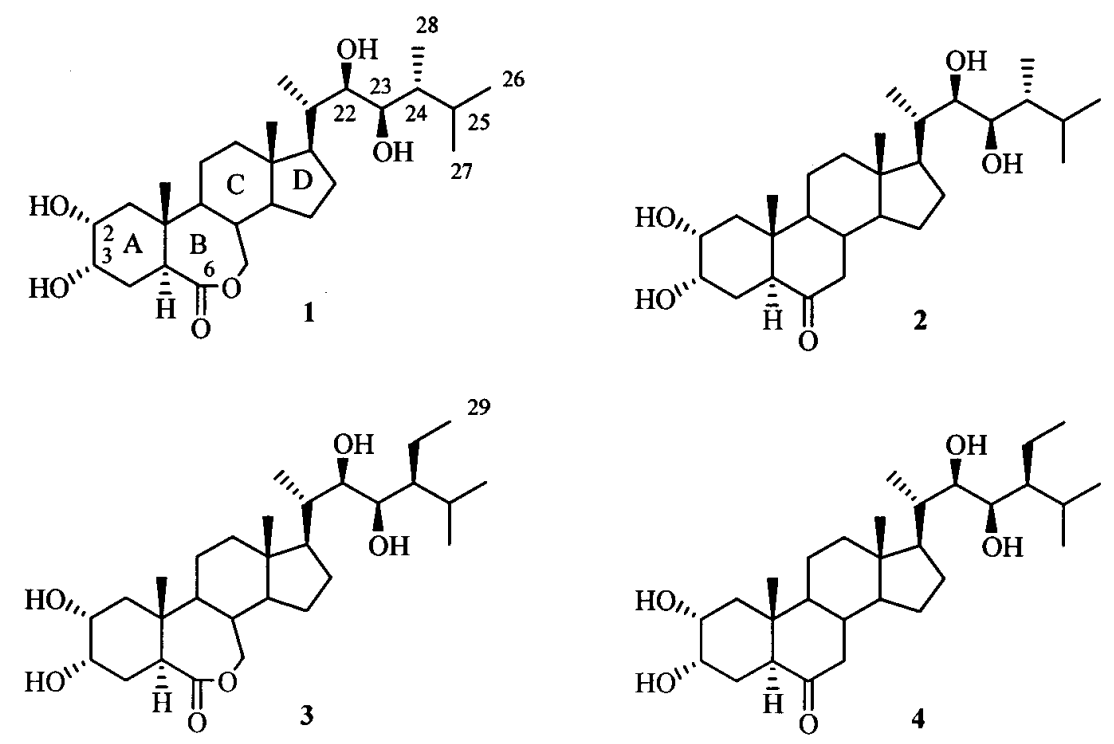

The carbon atoms in the brassinosteroid molecules are located near the plane formed by the rigidly fused rings of the steroid skeleton. The dashed lines in the formulas show that the functional groups or individual atoms, joined by single bonds to the skeleton of the molecule, are located in space below the plane of the molecule. The thick lines mean that the corresponding moieties are located above the plane. So far only brassinosteroids having such a spatial orientation of the $\mathrm{OH}$ groups at $\mathrm{C} 22$ and C 23, which is illustrated in the structural formulas ( $R$ configuration), have been observed in plants, while compounds with the opposite $S$ configuration of the $\mathrm{OH}$ groups can be obtained only synthetically. Substituents at C 24 of natural brassinosteroids can have both the $R$ configuration (compounds $\mathbf{1}, \mathbf{2}$ ) and the $S$ configuration $(\mathbf{3}, \mathbf{4})$.

The Experiment. The studied brassinosteroids were synthesized by the methods described in [6, 7]. They practically do not dissolve in the neutral liquids $\mathrm{CCl}_{4}$ and $\mathrm{CS}_{2}$, which are transparent in the IR region of the spectrum, and so we used $\mathrm{CHCl}_{3}$ and $\mathrm{CDCl}_{3}$. The concentration of brassinosteroids was no greater than $0.01 \mathrm{M}$ in these solvents. The cuvet thickness was $0.43 \mathrm{~mm}$. Films of the studied substances were obtained by evaporation of solutions of the compounds in $\mathrm{CHCl}_{3}$ on $\mathrm{NaCl}$ windows at room temperature and normal atmospheric pressure. The synthesized brassinosteroid substances were ground with anhydrous, finely dispersed $\mathrm{KBr}$, and the prepared powder was pressed under vacuum according to the standard procedure. The concentration of the studied substances, pressed in $\mathrm{KBr}$, was no greater than 0.1 mass $\%$.

The IR spectra of the brassinosteroid samples were recorded on a NEXUS IR Fourier spectrometer with OMNIC software in the range $4000-400 \mathrm{~cm}^{-1}$ with spectral resolution $2 \mathrm{~cm}^{-1}$ and 320 repeated scans. For accurate determination of the frequencies of the maxima $\left(v_{\max }\right)$ of the absorption bands in the IR spectra of the brassinosteroids, the contours of broadened and asymmetric bands were also separated into components by differentiation of the spectral curves, with analysis of the second derivatives $\left(d^{2} T / d v^{2}\right)$.

Results and Discussion. The studied brassinosteroids have similar chemical structures: two hydroxyl groups on the C 2 and C 3 carbon atoms of $\operatorname{ring} A$, and two hydroxyl groups with the $R$ configuration on the side chain for hydrocarbon atoms $\mathrm{C} 22$ and C 23, identical structure of rings $A, C, D$. However, there are also substantial differences in the structure of the $B$ ring, the substituents on the $\mathrm{C} 24$ atom, and their configurations.

Figure 1 shows the IR spectra in a broad range of frequencies for four compounds from the brassinosteroid class. The frequencies of the maxima for the absorption bands of the characteristic groups of atoms are shown in Table 1. In the high-frequency region of the IR spectra of brassinosteroids $\left(3490-3420 \mathrm{~cm}^{-1}\right)$, there are broad bands involving participation of stretching vibrations of associated $\mathrm{OH}$ groups. Brassinosteroids are in the crystalline state in $\mathrm{KBr}$.

In the structure of brassinosteroids, the hydrocarbon groups $\mathrm{CH}_{3}, \mathrm{CH}_{2}$, and $\mathrm{CH}$ are found on different rings and on the side chain. In this case, epibrassinosteroids differ from homobrassinosteroids in that a $\mathrm{CH}_{3}$ group with an $R$ configuration is bonded to the $\mathrm{C} 24$ atom of epibrassinosteroids, while a $\mathrm{CH}_{2}-\mathrm{CH}_{3}$ group with an $S$ configuration is involved for homobrassinosteroids; brassinolides differ from castasterones in the different bonding of the $\mathrm{CH}_{2}$ group 

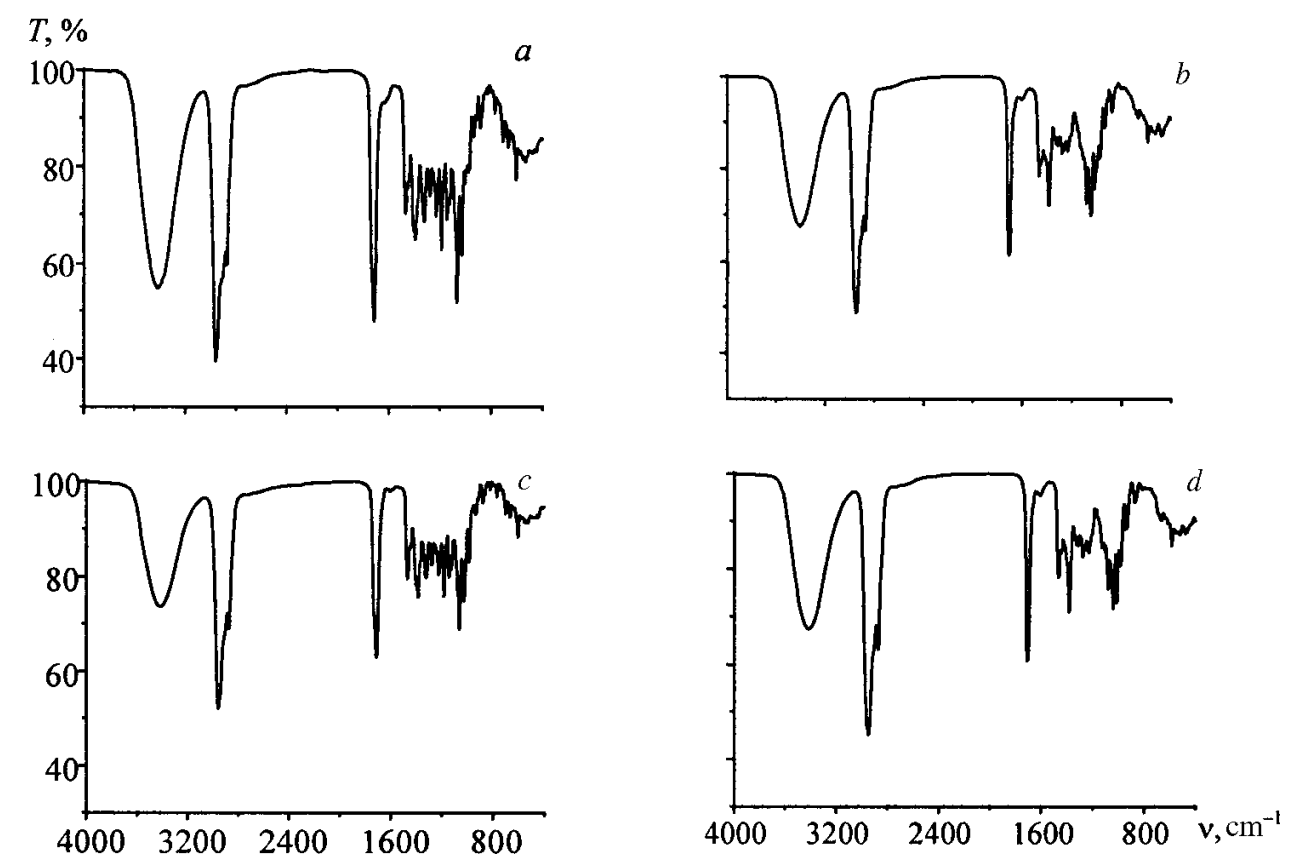

Fig. 1 IR spectra of 24-epibrassinolide (a), 24-epicastasterone (b), 28-homobrassinolide (c), and 28-homocastasterone (d), pressed in $\mathrm{KBr}$.

to adjacent atoms of the $B$ ring. The $\mathrm{CH}_{2}$ and $\mathrm{CH}$ groups in the same molecule are not equivalent. In the IR spectra of the studied brassinosteroids pressed in $\mathrm{KBr}$, the absorption in the $3000-2800 \mathrm{~cm}^{-1}$, consisting of a series of bands (Fig. 1), belong to stretching vibrations of the hydrocarbon groups. In Fig. 2, this region is shown on a larger scale, and the contours of the spectral absorption bands are differentiated: $d^{2} T / d v^{2}$ (curves 2).

In the absorption spectra of the studied brassinosteroids, there are five bands each belonging to stretching vibrations of the hydrocarbon groups. The most high-frequency strong (s) bands is assigned to antisymmetric vibrations of the $\mathrm{CH}_{3}$ groups. One significantly overlaps with another band (also strong), which is assigned to antisymmetric vibrations of the $\mathrm{CH}_{2}$ groups. The third band of medium intensity (m) belongs to the stretching vibrations of the $\mathrm{CH}$ groups. The last two bands (the fourth band $(\mathrm{m})$ and the fifth weak band $(\mathrm{w})$ ) are assigned to symmetric stretching vibrations of the $\mathrm{CH}_{3}$ and $\mathrm{CH}_{2}$ groups respectively. The overlapping bands of the antisymmetric stretching vibrations of these groups in brassinosteroids form a band with a characteristic contour. In the case of brassinolides, the intense band of the $\mathrm{CH}_{3}$ groups and the frequency of the maximum for the overall band is equal to $2960 \mathrm{~cm}^{-1}$ while in the corresponding spectra of castasterones, the intense band for the $\mathrm{CH}_{2}$ groups and the common maximum has a lower frequency: $2947 \mathrm{~cm}^{-1}$.

Significantly more information can be extracted from analysis of the differential spectra, shown in Fig. 2 (curves 2). The frequencies of the maxima for the bands and their assignment to the stretching vibrations of the $\mathrm{CH}_{3}$, $\mathrm{CH}_{2}$, and $\mathrm{CH}$ groups are shown in Table 1 .

In the structure of the studied brassinosteroids, there is an equal number of $\mathrm{CH}_{3}$ groups and they are joined to the skeleton of the molecules by identical $\mathrm{C}-\mathrm{CH}_{3}$ bonds. However, besides the bands belonging to antisymmetric and symmetric vibrations of these groups with practically indistinguishable frequencies $v_{\mathrm{as}} \approx 2970-2967 \mathrm{~cm}^{-1}$ and $v_{\mathrm{s}}$ $\approx 2870-2868 \mathrm{~cm}^{-1}$, in the differential spectra of brassinolides there is one more band $v_{\mathrm{as}}=2997 \mathrm{~cm}^{-1}$.

In brassinosteroid molecules, there are seven $\mathrm{CH}_{2}$ groups each included in the ring, while for homobrassinosteroids there is one more group each on the side chain. If all the $\mathrm{CH}_{2}$ groups were functionally identical, then in the IR spectra of each compound we would observe one band each for their antisymmetric and symmetric stretching vibrations. In the differential spectra (Fig. 2), two bands each, $v_{\mathrm{as}}$ and $v_{\mathrm{s}}$, belong to these groups (Table 1). The $\mathrm{O}=\mathrm{C}-\mathrm{O}$ group has a substantial effect on vibrations of the $\mathrm{CH}_{2}$ group that are part of the seven-membered $B$ ring of brassinolides, while the $\mathrm{C}=\mathrm{O}$ group has a substantial effect on the $\mathrm{CH}_{2}$ group that is part of the six-membered $B$ ring of brass- 

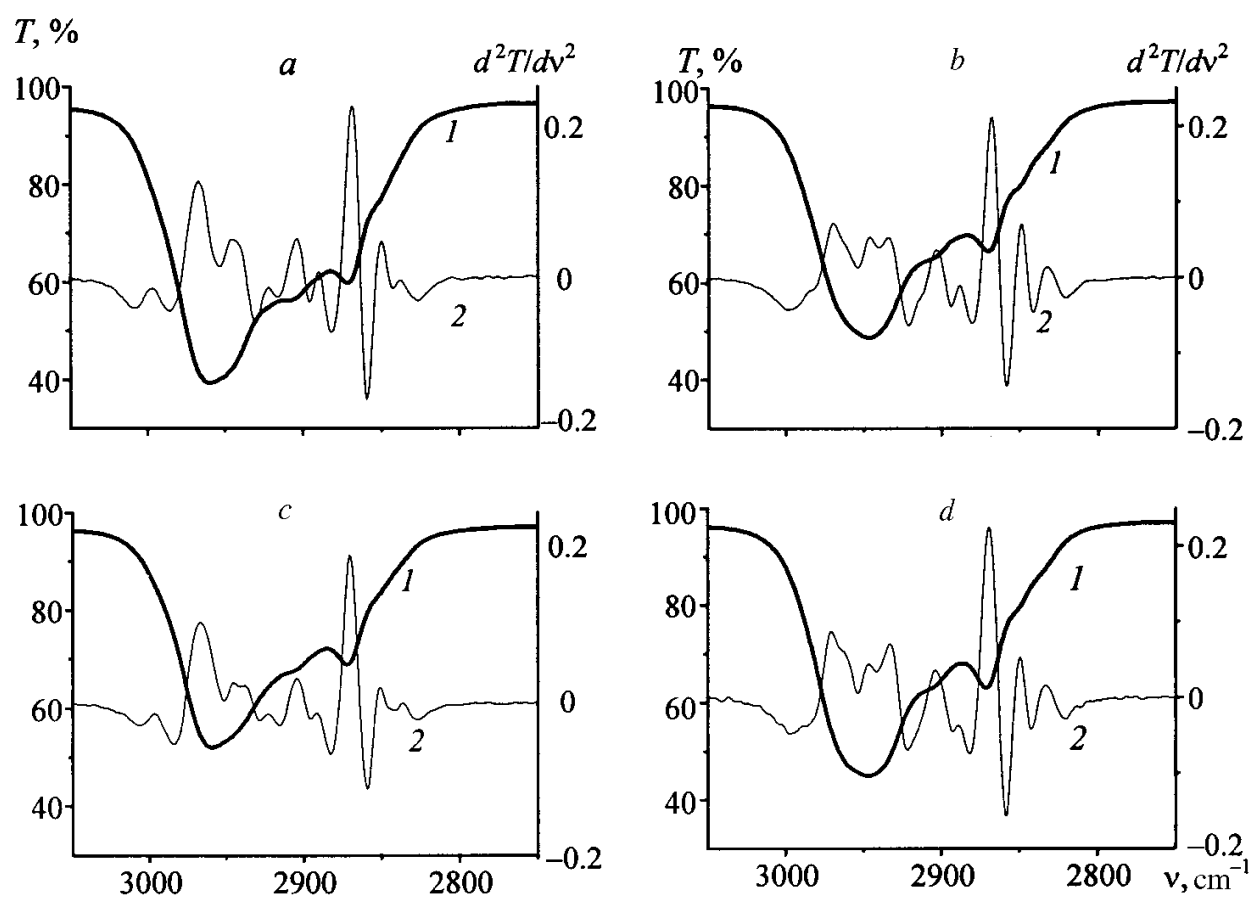

Fig. 2 IR spectra (1) and their second derivatives (2) in the region of the stretching vibrations of the $\mathrm{CH}_{3}, \mathrm{CH}_{2}$, and $\mathrm{CH}$ groups of 24-epibrassinolide (a), 24-epicastasterone (b), 28-homobrassinolide (c), and 28-homocastasterone (d), pressed in $\mathrm{KBr}$.

TABLE 1 Frequencies of Maxima $\left(v_{\max }, \mathrm{cm}^{-1}\right)$ for IR Absorption Bands for Stretching Vibrations of Groups of Atoms in Brassinosteroids Pressed in $\mathrm{KBr}$

\begin{tabular}{|c|c|c|c|c|c|}
\hline Characteristic group & Type of vibration & 24-Epibrassinolide & 24-Epicastasterone & 28-Homobrassinolide & 28-Homocastasterone \\
\hline $\mathrm{OH}$ & $v(\mathrm{OH})$ & 3413 & 3405 & 3415 & 3408 \\
\hline \multirow[t]{2}{*}{$\mathrm{CH}_{3}$} & $v_{\mathrm{as}}(\mathrm{CH})$ & $\begin{array}{l}2997 \\
2967 \\
\end{array}$ & $\begin{array}{c}- \\
2970 \\
\end{array}$ & $\begin{array}{l}2997 \\
2967 \\
\end{array}$ & $\begin{array}{c}- \\
2970 \\
\end{array}$ \\
\hline & $v_{\mathrm{s}}(\mathrm{CH})$ & 2868 & 2868 & 2870 & 2869 \\
\hline \multirow{2}{*}{$\mathrm{CH}_{2}$} & $\left.\mathrm{vas}_{\mathrm{as}} \mathrm{CH}\right)$ & $\begin{array}{l}2945 \\
2938 \\
\end{array}$ & $\begin{array}{l}2946 \\
2934 \\
\end{array}$ & $\begin{array}{l}2945 \\
2938 \\
\end{array}$ & $\begin{array}{l}2946 \\
2933 \\
\end{array}$ \\
\hline & $v_{S}(\mathrm{CH})$ & $\begin{array}{l}2850 \\
2838 \\
\end{array}$ & $\begin{array}{l}2849 \\
2833 \\
\end{array}$ & $\begin{array}{l}2851 \\
2836 \\
\end{array}$ & $\begin{array}{l}2849 \\
2833 \\
\end{array}$ \\
\hline $\mathrm{CH}$ & $v(\mathrm{CH})$ & $\begin{array}{l}2922 \\
2904 \\
2890 \\
\end{array}$ & $\begin{array}{c}- \\
2903 \\
2889 \\
\end{array}$ & $\begin{array}{l}2923 \\
2904 \\
2891 \\
\end{array}$ & $\begin{array}{c}- \\
2903 \\
2889 \\
\end{array}$ \\
\hline $\mathrm{C}=\mathrm{H}$ & $v(\mathrm{C}=\mathrm{O})$ & $\begin{array}{l}1735 \\
1710 \\
\end{array}$ & $\begin{array}{l}1714 \\
1698 \\
\end{array}$ & $\begin{array}{l}1736 \\
1712 \\
\end{array}$ & $\begin{array}{l}1714 \\
1698 \\
\end{array}$ \\
\hline $\mathrm{C}-\mathrm{O}-\mathrm{C}=\mathrm{O}$ & $v(\mathrm{C}-\mathrm{O})$ & 1184 & - & 1185 & - \\
\hline
\end{tabular}

inolide. This is confirmed by the higher values of the frequencies $v_{\mathrm{as}}=2938 \mathrm{~cm}^{-1}$ for brassinolides than for the corresponding frequencies $v_{\mathrm{as}} \approx 2933 \mathrm{~cm}^{-1}$ for castasterones. We know that a direct bond between the functional groups and the oxygen atom increases their vibrational frequencies. The relationship between the symmetric vibrations of these groups is similar in the spectra of brassinolides and castasterones. The bands for the stretching vibrations of the re- 

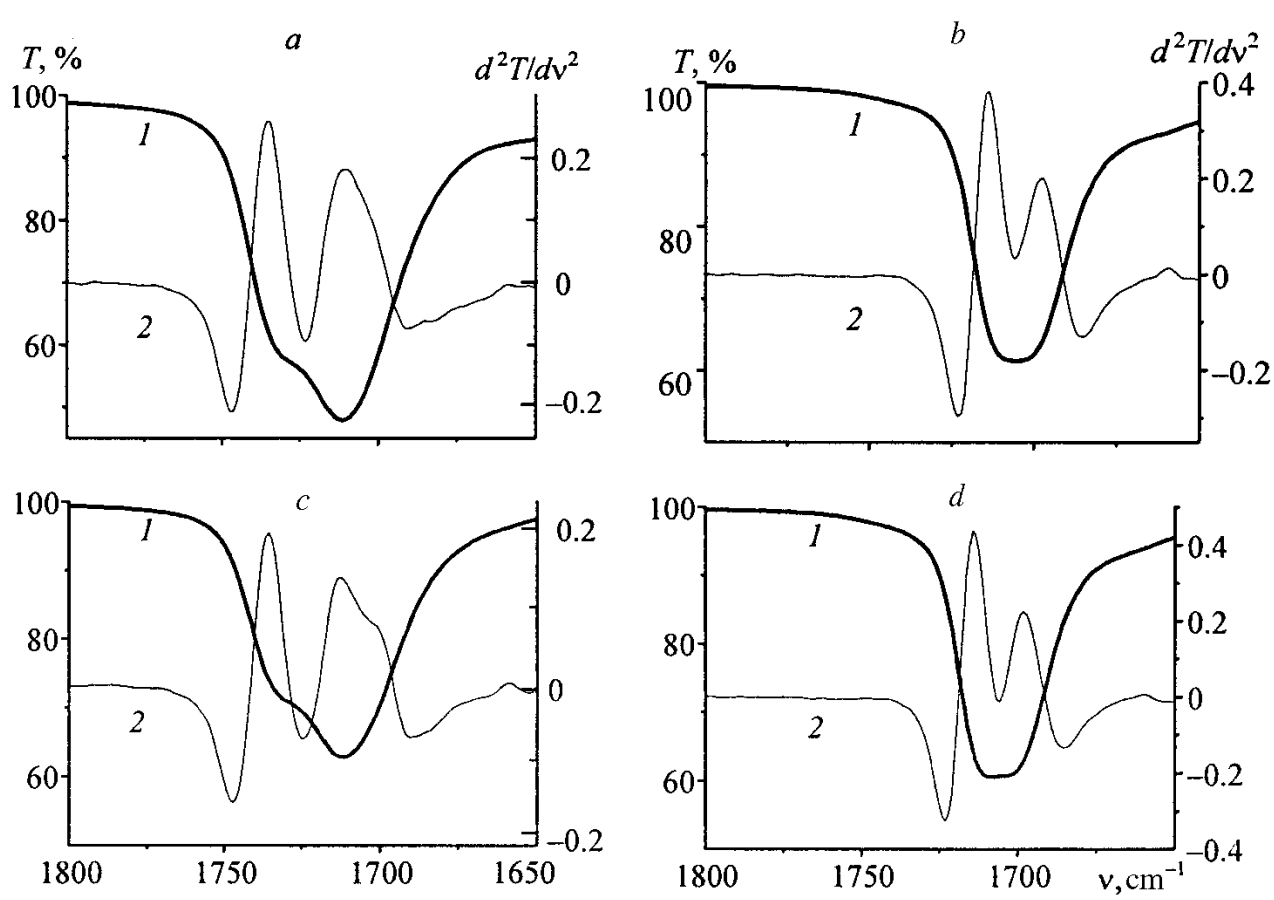

Fig. 3 IR spectra (1) and their second derivatives (2) in the region of the stretching vibrations of the $\mathrm{C}=\mathrm{O}$ groups of 24-epibrassinolide (a), 24-epicastasterone (b), 28-homobrassinolide (c), and 28-homocastasterone (d), pressed in $\mathrm{KBr}$ according to the standard procedure.

TABLE 2 Frequencies of Maxima $\left(v_{\max }, \mathrm{cm}^{-1}\right)$ for IR Absorption Bands for Stretching Vibrations of $\mathrm{C}=\mathrm{O}$ Groups in IR Spectra of Brassinosteroid Solutions and the Solid Phase

\begin{tabular}{|c|c|c|c|c|c|}
\hline \multirow{3}{*}{ Compound } & \multicolumn{3}{|c|}{ Solution } & \multirow{3}{*}{ Film } & \multirow{3}{*}{ Pressed in $\mathrm{KBr}$} \\
\hline & \multicolumn{2}{|c|}{ in $\mathrm{CHCl}_{3}$} & in $\mathrm{CDCl}_{3}$ & & \\
\hline & $0.01 \mathrm{M}$ & $0.001 \mathrm{M}$ & $0.004-0.001 \mathrm{M}$ & & \\
\hline \multirow{2}{*}{ 24-Epibrassinolide } & 1721 & 1720 & 1719 & 1729 & 1735 \\
\hline & - & - & - & 1709 & 1710 \\
\hline \multirow{2}{*}{ 24-Epicastasterone } & 1704 & 1704 & 1704 & 1709 & 1714 \\
\hline & - & - & - & 1698 & 1698 \\
\hline \multirow{2}{*}{ 28-Homobrassinolide } & 1720 & 1721 & 1720 & 1731 & 1736 \\
\hline & - & - & - & 1711 & 1712 \\
\hline \multirow{2}{*}{ 28-Homocastasterone } & 1703 & 1704 & 1704 & 1713 & 1714 \\
\hline & - & - & - & 1700 & 1698 \\
\hline
\end{tabular}

maining $\mathrm{CH}_{2}$ groups that are part of the structure of the studied molecules, also including the $\mathrm{CH}_{2}$ of the side chain of homobrassinosteroids, have practically identical frequencies for both $v_{\mathrm{as}}$ and $v_{\mathrm{s}}$ (Table 1).

The $\mathrm{CH}$ groups in the structure of brassinosteroids are also not spectrally equivalent. Four of them are bonded to $\mathrm{OH}$ groups of the $A$ ring and the side chain, five are found in the rings, three are bonded to $\mathrm{CH}_{3}$ groups on the side chain, and for homobrassinosteroids, one is joined to a $\mathrm{CH}_{2}$ group. In the differential spectra of brassinolides, we observe three bands, while for castasterones we observe two bands, assigned to the stretching vibrations of these groups. We can hypothesize that the bands with frequency of the maximum $v=2904 \pm 1 \mathrm{~cm}^{-1}$ are assigned to stretching vibrations of $\mathrm{CH}$ groups in $\mathrm{H}-\mathrm{C}-\mathrm{OH}$, and the lower-frequency bands, also having practically identical frequencies for all the studied brassinosteroids, belong to the rest of the $\mathrm{CH}$ groups. Then the high-frequency bands $\mathrm{v}=$ 
TABLE 3 Frequencies of Maxima $\left(v_{\max }, \mathrm{cm}^{-1}\right)$ for Absorption Bands for Stretching Vibrations of OH Groups in IR Spectra of Brassinosteroid Solutions and the Solid Phase

\begin{tabular}{|c|c|c|c|c|}
\hline \multirow{3}{*}{ Compound } & \multicolumn{2}{|c|}{ Solution } & \multirow{3}{*}{ Film } & \multirow{3}{*}{ Pressed in $\mathrm{KBr}$} \\
\hline & in $\mathrm{CHCl}_{3}$ & in $\mathrm{CDCl} 3$ & & \\
\hline & $0.002 \mathrm{M}$ & $0.002 \mathrm{M}$ & & \\
\hline \multirow{3}{*}{ 24-Epibrassinolide } & 3623 & 3621 & - & - \\
\hline & 3581 & 3586 & - & - \\
\hline & - & - & 3421 & 3413 \\
\hline \multirow{3}{*}{ 24-Epicastasterone } & 3624 & 3624 & - & - \\
\hline & 3574 & 3577 & - & - \\
\hline & - & - & 3414 & 3405 \\
\hline \multirow{3}{*}{ 28-Homobrassinolide } & 3621 & 3623 & - & - \\
\hline & 3584 & 3581 & - & - \\
\hline & - & - & 3430 & 3415 \\
\hline \multirow{3}{*}{ 28-Homocastasterone } & 3621 & 3620 & - & - \\
\hline & 3582 & 3583 & - & - \\
\hline & - & - & 3425 & 3408 \\
\hline
\end{tabular}

$2922 \pm 1 \mathrm{~cm}^{-1}$ in the spectra of epibrassinolides and homobrassinolides should be assigned to $\mathrm{CH}$ groups bonded to the seven-membered $B$ ring.

From analysis of the data obtained, it follows that the IR spectra of brassinolides in the region of the stretching vibrations of the $\mathrm{CH}_{3}, \mathrm{CH}_{2}$, and $\mathrm{CH}$ groups are significantly different from the spectra of castasterones. These differences in the spectra should be associated with the influence of the structure and configuration of the $B$ ring on the hydrocarbon groups added to it.

Within the structure of the molecules of the studied brassinosteroids, there is one carbonyl group each on the $B$ ring. Intense, complex bands in the IR spectra of brassinosteroids pressed in $\mathrm{KBr}, v_{\max } \approx 1710 \mathrm{~cm}^{-1}$ (Fig. 1), belong to stretching vibrations of these groups. In the absorption spectra on a larger scale and the differential spectra (curves 2), shown in Fig. 3, we observe two bands each, belonging to the stretching vibrations of the $\mathrm{C}=\mathrm{O}$ groups. They also occur in the spectra of films of these compounds. The frequencies of their maxima are given in Table 2. Compounds 1,2 and especially 3,4 dissolve poorly even in the polar solvents $\mathrm{CHCl}_{3}$ and $\mathrm{CDCl}_{3}$. The maximum concentration of the solutions was $0.01 \mathrm{M}$. At these and lower concentrations, in the spectra of solutions of all the studied brassinosteroids we observe one band each for the stretching vibrations of the $\mathrm{C}=\mathrm{O}$ groups (Table 2).

From analysis of the data obtained, we can draw the following conclusions. The low-frequency bands in the IR spectra of the solid phase belong to the stretching vibrations of associated $\mathrm{C}=\mathrm{O}$ groups. They can engage in a hydrogen bond with the $\mathrm{OH}$ groups. The absence of these bands in the spectra of the solutions is proof for an intermolecular hydrogen bond $\mathrm{C}=\mathrm{O} \cdots \mathrm{H}-\mathrm{O}$ but not for an intramolecular hydrogen bond. In all the studied media, the frequencies of the vibrations of the $\mathrm{C}=\mathrm{O}$ groups of the brassinolides are higher than the corresponding frequencies of the castasterones, which is associated with the influence of the oxygen of the seven-membered $B$ ring.

Usually the frequencies of the stretching vibrations of free $\mathrm{C}=\mathrm{O}$ groups of the compounds are higher in solutions than in the solid phase. In this case, the relationship between the corresponding frequencies is the reverse (Table 2). This is connected with formation of weak associates between the oxygen of the carbonyl group and the hydrogen or deuterium of the polar solvents: $\mathrm{C}=\mathrm{O} \cdots \mathrm{HCCl}_{3}$ and $\mathrm{C}=\mathrm{O} \cdots \mathrm{DCCl}_{3}$.

In the IR spectra of the films and the brassinosteroids pressed in $\mathrm{KBr}$, we observed one broad absorption band each, $v_{\max } \approx 3430-3405 \mathrm{~cm}^{-1}$, assigned to associated $\mathrm{OH}$ groups. The frequencies of their maxima $v_{\max }$ are given in Table 3. They are $8-17 \mathrm{~cm}^{-1}$ higher in the spectra of the films, due to the different physical properties of the films and the pressed samples. For both media, the values of (max for these bands are higher in the spectra of the brassinolides. In the spectra of solutions of brassinosteroids in $\mathrm{CHCl}_{3}$ and $\mathrm{CDCl}_{3}$ at concentrations of $0.002 \mathrm{M}$ or lower, we recorded two narrow bands each, with significantly higher frequencies $v_{\max }$ than in the spectra of the solid 
phase. The highest frequency band has the same value $v_{\max }^{1}=3622 \pm 1 \mathrm{~cm}^{-1}$ in the spectra of all the studied brassinosteroids. The frequency of the maxima for the second band is lower than for the first by $\approx 40 \mathrm{~cm}^{-1}$ and all the compounds have close values for this frequency: $v_{\max }^{2}=3581 \pm 3 \mathrm{~cm}^{-1}$ (see Table 3). The spectra of solutions of brassinosteroids in $\mathrm{CHCl}_{3}$ and $\mathrm{CDCl}_{3}$ are practically identical. In these solutions, associates of $\mathrm{H}$ and $\mathrm{D}$ with the $\mathrm{OH}$ groups of the brassinosteroids can form, but they are weaker than their associates with the $\mathrm{C}=\mathrm{O}$ groups.

The brassinosteroid structure has two $\mathrm{OH}$ groups each on the $A$ ring, located below the plane of the molecule, and two on the side chain. Broad bands with $v_{\max } \approx 3430-3405 \mathrm{~cm}^{-1}$ in the spectra of the solid phase of the brassinosteroids are assigned to $\mathrm{OH}$ groups forming an intermolecular hydrogen bond, since they are missing in the spectra of the solutions. From $x$-ray diffraction analysis of the crystals of the epicastasterone derivative, whose structure has only two $\mathrm{OH}$ groups, intermolecular hydrogen bonds are formed in them between atoms of the group on the $A$ ring of one molecule and the $\mathrm{OH}$ group of the side chain of another molecule. The carbonyl group does not participate in the association [8]. In the studied brassinosteroids, intermolecular hydrogen bonds are formed both between the $\mathrm{OH}$ groups and with the $\mathrm{C}=\mathrm{O}$ groups, since in the spectra of the solid phase of the brassinosteroids we observe bands not only for free carbonyl groups but also for ones bound to an $\mathrm{OH}$ group. The overtones of the carbonyl groups also participate in formation of the broad bands $v_{\max } \approx 3430-3405 \mathrm{~cm}^{-1}$. Using an IR microscope, we obtained the IR spectra of brassinosteroid crystallites. In each of these broad, structureless bands, we see 2-3 poorly resolved bands.

The high-frequency bands $v_{\max }^{1}$ and $v_{\max }^{2}$ in the spectra of brassinosteroid solutions are assigned to $\mathrm{OH}$ groups not participating in intermolecular hydrogen bonds. The hydroxyl groups on the $A$ ring are sufficiently close and can form an intramolecular hydrogen bond, as a result of which a band appears in the spectrum with frequency $v_{\max }^{2}, \approx 40$ $\mathrm{cm}^{-1}$ lower than the frequency of the free $\mathrm{OH}$ groups $v_{\max }^{1}=3622 \pm 1 \mathrm{~cm}^{-1}$. However, the $\mathrm{OH}$ groups that are part of the $A$ ring and the side chain are not equivalent. We can hypothesize that the band with frequency $v_{\max }^{1}$ is assigned to free $\mathrm{OH}$ groups of the side chain, while $v_{\max }^{2}$ is assigned to free $\mathrm{OH}$ groups of the $A$ ring. In order to unambiguously establish the nature of these bands, we need to carry out studies of the IR spectra of brassinosteroids with different numbers and positions of the hydroxyl groups within their structures.

Conclusion. We have established a number of spectral signs allowing us to identify 24-epibrassinolides, 28homobrassinolides, and 24-epicastasterones, 28-homocastasterones. The structures of these brassinosteroids contain an identical number of $\mathrm{CH}_{3}$ and $\mathrm{CH}$ groups, practically identically bonded to the skeleton of the molecule. In the IR spectra of the brassinolides, besides the bands with identical frequencies for these groups, for all the studied compounds there are bands with higher frequencies, $v_{\mathrm{as}}=2997 \mathrm{~cm}^{-1}\left(\mathrm{CH}_{3}\right)$ and $v=2922 \mathrm{~cm}^{-1}(\mathrm{CH})$. It is only in the spectra of the brassinolides that we observe bands with $v=1184 \mathrm{~cm}^{-1}$ for stretching vibrations of the $\mathrm{C}-\mathrm{O}$ group that is part of the $\mathrm{C}-\mathrm{O}-\mathrm{C}=\mathrm{O}$ group on the seven-membered $B$ ring. The frequencies of the stretching vibrations for the $\mathrm{C}=\mathrm{O}$ groups are also higher for the brassinolides. These spectral differences are associated with the structural and configurational features of the $B$ rings of brassinolides and castasterones.

In the IR spectra of brassinosteroids pressed in $\mathrm{KBr}$ and their films, we recorded two bands each, assigned to stretching vibrations of the carbonyl groups: the high-frequency bands belong to free $\mathrm{C}=\mathrm{O}$ groups, while the low-frequency bands belong to the hydrogen bond formed with the $\mathrm{OH}$ groups. In these media, we observe only bands for bound $\mathrm{OH}$ groups.

In the spectra of solutions of brassinosteroids in $\mathrm{CHCl}_{3}$ and $\mathrm{CDCl}_{3}$, there is one band each for the free $\mathrm{C}=\mathrm{O}$ groups, while two bands each belong to the $\mathrm{OH}$ groups, the corresponding frequencies of which $v_{\max }^{1}=3622 \pm 1 \mathrm{~cm}^{-1}$ and $v_{\max }^{2}=3581 \pm 3 \mathrm{~cm}^{-1}$ are identical for the brassinolides and castasterones. The high-frequency band $v_{\max }^{1}$ is assigned to stretching vibrations of free $\mathrm{OH}$ groups on the side chain, while $v_{\max }^{2}$ should be assigned to the $\mathrm{OH}$ groups on the $A$ ring, forming an intramolecular hydrogen bond.

This work was done with the support of the International Scientific and Technical Center (project 1332).

\section{REFERENCES}

1. W.-S. Zhou, B. Jiang, and X.-fu Pan, Tetrahedron, 46, 3173-3188 (1990).

2. M. J. Tompson, W. J. Meudt, N. B. Mandava, S. R. Dutky, W. R. Lusby, and D. W. Spaulding, Steroids, 39, 89-105 (1992).

3. V. A. Khripach, V. N. Zhabinskii, and A. E. de Groot, Brassinosteroids. A New Class of Plant Hormones, Academic Press, San Diego (1999). 
4. C. Brosa, J. M. Capdevila, and J. Zamora, Tetrahedron, 52, 2435-2448 (1996).

5. M. D. Grove, G. F. Spencer, W. K. Rohwedder, N. B. Mandava, J. F. Worley, J. D. Warthen, Jr., G. L. Flippen-Anderson, and J. C. Cook, Jr., Nature, 281, 216-217 (1979).

6. V. A. Khripach, V. N. Zhabinskii, V. K. Ol'khovik, G. V. Ivanova, E. V. Zhernosek, and A. I. Kotyatkina, Zh. Org. Khim., 30, 1650-1655 (1994).

7. F. A. Lakhvich, V. A. Khripach, N. V. Kovganko, and V. N. Zhabinskii, "(22R,23R,24S)-22,23-Dihydroxy-24ethyl-5 $\alpha$-cholest-2-en-6-one as an intermediate in synthesis of (24S)-24-ethylbrassinone and a method for obtaining it," USSR Inventor's Certificate No. 1363830 (1987).

8. A. Kolbe, P. Fuchs, A. Porzel, U. Baumeister, A. Kolbe, and G. Adam, J. Chem. Soc. Trans. I, 2022-2027 (2002). 